University of Windsor

Scholarship at UWindsor

Summer 2012

\title{
An integrated multiple criteria preference ranking approach to the Canadian west coast port congestion conflict
}

Ginger Y. Ke

Kevin W. Li Dr.

University of Windsor

Keith W. Hipel

Follow this and additional works at: https://scholar.uwindsor.ca/odettepub

Part of the Business Commons

\section{Recommended Citation}

Ke, Ginger Y.; Li, Kevin W. Dr.; and Hipel, Keith W.. (2012). An integrated multiple criteria preference ranking approach to the Canadian west coast port congestion conflict. Expert Systems with Applications, 39 (10), 9181-9190.

https://scholar.uwindsor.ca/odettepub/57

This Article is brought to you for free and open access by the Odette School of Business at Scholarship at UWindsor. It has been accepted for inclusion in Odette School of Business Publications by an authorized administrator of Scholarship at UWindsor. For more information, please contact scholarship@uwindsor.ca. 


\title{
An integrated multiple criteria preference ranking approach to the Canadian west coast port congestion conflict
}

\author{
Ginger Y. Ke ${ }^{\mathrm{a}}$, Kevin W. Li ${ }^{\mathrm{b}, \mathrm{c}^{*}}$, and Keith W. Hipel ${ }^{\mathrm{d}}$ \\ ${ }^{a}$ Department of Management Sciences, University of Waterloo, Waterloo, Ontario N2L 3G1, Canada \\ ${ }^{b}$ Odette School of Business, University of Windsor, Windsor, Ontario N9B 3P4, Canada \\ ${ }^{c}$ Department of Value and Decision Science, Tokyo Institute of Technology, W9-38, 2- \\ 12-1 Ookayama, Meguro, Tokyo 152-8552, Japan \\ ${ }^{d}$ Department of Systems Design Engineering, University of Waterloo, Waterloo, Ontario N2L 3G1, \\ Canada
}

\begin{abstract}
:
An integrative conflict analysis approach, incorporating an Analytic Hierarchy Process (AHP) based preference ranking method into the Graph Model for Conflict Resolution (GMCR), is employed to investigate the Canadian west coast port congestion dispute. The Canadian west coast has historically been an important gateway connecting North America to Asia thanks to its specific geographical and strategic location. Despite successful operations and maintenance of the port facilities to handle international trade during the past few decades, the west coast is now facing increasing congestion problems, resulting in significant delays in transporting goods from the west coast to other parts of Canada and the USA. The strategic analyses carried out in this research suggest potential resolutions in which Canada would expand port facilities at various locations, encouraging traders to continue choosing the Canadian west coast as one of their trade gateways to North America.
\end{abstract}

Keywords: AHP, integrative conflict analysis, graph model, Canadian west coast port congestion, preference

\section{INTRODUCTION}

Traffic congestions always have significant impacts on the entire supply chain operations. Currently, the Canadian west coast is facing increasing congestion problems caused by the recent explosive increase in the trading volume with Asia, especially China. This serious congestion results in considerable delays in receiving goods from other countries and transporting goods from the west coast to other parts of Canada and the USA.

"Corresponding author. Tel.: 1 (519) 253-3000 ext 3456. Fax: 1 (519) 973-7073. Email: kwli@uwindsor.ca. 
Generally, the west coast of Canada refers to British Columbia (BC), the westernmost Canadian province. As the key connection point in the Asia-Pacific Gateway, the BC port system has always been and will continue to be the most critical aspect of the economic future of Canada, and perhaps even the entire North American continent. Nevertheless, the recent booming trade between Asian countries and North America has brought serious concerns to all Canadian west coast ports. The Port of Vancouver (it was merged with Fraser River Port and North Fraser Port into a large entity known as Port Metro Vancouver now), Canada's largest and most diversified port, for example, is already handling a significantly large container business of 1,767,379 TEUs (20-foot-equivalent units) in 2005, which is forecasted to be tripled within 15 years (Ryan, 2006a). But the existing port capacity cannot handle such a massive amount. By 2020, the container cargo going through British Columbian ports and the value of this trade are projected to expand to 5 to 7 million containers and $\$ 75$ billion, thereby increasing by about $300 \%$ and $114 \%$, respectively (Transport Canada, 2005). Some statistical data provide further description of this situation: the world gross domestic product in the past twenty years has increased 2.8\% annually; global container trade has increased about $9 \%$ annually; more than 140 jumbo containerships of 8,000 to 10,000 TEUs capacity will be sailing on the world's oceans within five years. These capacity crises, due to exponentially increasing trade, are faced by all Canadian ports and generate immense pressure on Canadian transportation systems. Norman Stark, President and CEO of TSI Terminal Systems, put forward the following five issues in September 2005, when attending the annual Port Days Conference (Smyrlis, 2005): 1) congested terminals; 2) shortage of longshore labour; 3) strained road and rail infrastructure; 4) scarcity of land for port expansions; and 5) increasing investment costs. Each issue poses a real challenge to Canada.

Meanwhile, the US ports are also experiencing a serious congestion situation. The huge amounts of international trading are "straining the supporting infrastructure" and significantly delaying all activities within supply chains (Sowinski, 2007). Pennsylvania State University recently studied 24 major US and Canadian ports and stated that west coast ports are underestimating expected future container volumes by as much as 11 million TEUs in 2015. "Delays due to congestion at west coast ports could then cause a 
domino effect" (Ryan, 2006a). More specifically, Seattle, for instance, is the fastestgrowing port in North America. From 2004 to 2005, its box volume has risen by 18\% to more than 2 million TEUs. In response to the volume growth, Seattle expects to increase its processing capacity by $10 \%$ after a new terminal project is completed by 2008 (Ryan, 2006a). In fact, this type of growth will continue well into the future. Such expansions are taking place in other locations along the US west coast, such as Los Angeles and San Diego, as well as some east coast ports. Nevertheless, the expanded capacity still does not seem to be able to keep pace with the rapid growth of international trade.

Facing all these challenges, Canadians have also come to realize some opportunities. As Stephen Poloz, Senior Vice-president, Corporate Affairs and Chief Economist of the Export Development Corporation (EDC) indicated (Ryan, 2006b), "Over the next five years, port capacity in Asia is slated to double. But in the United States, a lot of investments (since 9/11) are being funnelled into security rather than capacity." Accordingly, it is possible for Canadian ports to act as "a facilitator of US trade", not only because Canada is geographically located closest to Europe and Asia among the three countries involved in the North American Free Trade Agreement (NAFTA), but also due to Canada's lowest administrative burden (Brooks, 2007). Therefore, a key purpose of this paper is to suggest how Canada can seek opportunities for maximizing its benefit from this role.

Port research has been conducted from many different methodological viewpoints (Woo et al, 2011). Distinct from previous literature, this work focuses on the strategic perspective, aiming to develop an integrative conflict analysis approach (Ke et al., 2007), which incorporates an Analytic Hierarchy Process (AHP) (Satty, 1980, 1982, 1995, 2001; Chang et al., 2007) based preference ranking method into the Graph Model for Conflict Resolution (GMCR) (Fang et al., 1993), to examine the Canadian west coast port congestion problem. GMCR is a systematic procedure that handles complicated strategic decision problems involving two or more decision-makers (DMs) with differing objectives as reflected by their diverse preferences over possible states or outcomes. Due to its simplicity and flexibility, the graph model enables interested parties or an analyst to analyze a conflict and obtain a better understanding about what is currently happening and what could eventually take place (Fang et al., 1993). At the modeling stage, the 
determination of relative preferences for each DM is one of the most important elements as each involved party usually has different preferences over options, situations, and/or states; and a compromise or consensus, if any, will be achieved according to these preferences. From each DM's standpoint, it is inevitably appealing to consider multiple criteria when preferences are ranked over feasible states. If each state is regarded as a decision alternative in the ranking process, preference elicitation can be naturally treated as a typical Multiple Criteria Decision Analysis (MCDA) problem. As a useful MCDA technique, the Analytic Hierarchy Process (AHP) (Saaty, 1980, 1982, 1995, 2001) provides a mathematical procedure to take both quantitative and qualitative criteria into consideration in ranking decision alternatives. In this paper, the AHP approach is adapted to elicit preference rankings for each DM, which are then fed into a decision support system (DSS), GMCR II (Fang et al., 2003a, 2003b), to carry out a standard graph model stability analysis.

The remainder of the paper is organized as follows. In the second section, the basic methodology utilized in the application is described. Section III develops the conflict model for the Canadian west coast congestion problem and explains the preference derivation procedure from the AHP method. Section IV furnishes useful structural insights garnered from the strategic analysis. The paper concludes with some remarks in Section V.

\section{DESCRIPTION OF THE METHODOLOGY}

In this section, basics are first introduced about the graph model and its associated DSS, GMCR II. Then, the AHP approach is briefly explained with a focus on its structural features and practical procedures for utilizing the approach to derive preference information that will be incorporated into the graph model for carrying out the strategic analysis.

\subsection{The Graph Model for Conflict Resolution}

The Graph Model for Conflict Resolution is a simple but flexible methodology that is designed to analyze conflicts arising from a wide range of areas, such as environmental management, labour-management negotiations, military strategies, and peace-keeping activities, to name a few (Kilgour and Hipel, 2005). The graph model allows interested 
parties to put complicated strategic decision problems into perspective and attain a better understanding about the current situation as well as envisioning potential resolutions (Fang et al., 1993). In this section, a brief introduction is provided for the graph model and its associated DSS, GMCR II.

GMCR has its root in game theory and takes advantage of a graph representation to characterize DMs' moves and countermoves in a conflict. This methodology consists of four basic components (Fang et al., 1993): 1) a set of DMs, $N=\{1,2, \ldots, n\} ; 2$ ) a set of nodes, $S=\left\{s_{1}, s_{2}, \ldots, s_{m}\right\}$, where each node represents a feasible state describing a distinguishable scenario of the conflict; 3) a collection of finite directed graphs $\left\{D_{i}=\left(S, A_{i}\right), i \in N\right\}$ to track unilateral moves for each DM $i$, where $D_{i}$ is the directed graph for DM $i$ and $A_{i}$ is DM $i$ 's set of directed arcs in $D_{i}$, for which each arc stands for a move DM $i$ can make in one step between two states; and 4) each DM's relative preferences over $S$.

Note that, although all DMs share the same set of states, their rankings of the states according to preference usually differ due to their divergent interests. For a certain DM $i$, the relative preferences over the set of states, $S$, can be represented by binary relations $\left\{\succ_{i}, \sim_{i}\right\}$ on $S$, where for any two states $s$ and $q, s \succ_{i} q$ indicates that DM $i$ strictly prefers $s$ over $q$, and $s \sim_{i} q$ indicates that DM $i$ equally prefers $s$ and $q$. This pair of binary relations constitutes a preference structure with the following properties:

1) $\succ_{i}$ is asymmetric, i.e., it cannot occur that both $s \succ_{i} q$ and $q \succ_{i} s$;

2) $\sim_{i}$ is reflexive and symmetric, i.e., $s \sim_{i} s$ and if $s \sim_{i} q$, then $q \sim_{i} s$; and

3) $\left\{\succ_{i}, \sim_{i}\right\}$ is strongly complete, i.e., one and only one of the following three relations holds true: $s \succ_{i} q, q \succ_{i} s$, or $s \sim_{i} q$.

When DMs' moves and countermoves are assessed, it is reasonable to assume that each DM can only move from one state to another unilaterally, where the other DMs' actions are fixed. When he or she prefers to stay at a state, or in other words, does not have the motivation to move away from this state unilaterally, this state is said to be stable for the given DM. An equilibrium is obtained when a state is stable for all DMs under a certain stability definition, referred to as a solution concept. A predicted equilibrium usually 
corresponds to a potential resolution for this conflict model (Fang et al., 1993; Kilgour et al., 1996; Kilgour and Hipel, 2005).

In the graph model, several distinct solution concepts are employed to define stability, thereby capturing DMs' different behavioural and decision patterns in the face of conflict. The main stability definitions currently considered by GMCR include Nash Stability (Nash), General Metarationality (GMR), Symmetric Metarationality (SMR), Sequential Stability (SEQ), Limited Move Stablity $\left(L_{h}\right)$, and Non-Myopic Stability (NM). Table 1 shows a list of these solution concepts with their descriptions and associated characteristics. As an important feature, foresight refers to a DM's capacity to foresee possible future moves under a particular stability definition. As shown in Table 1, Nash stability has the lowest foresight, while non-myopic stability has the highest. The strategic disimprovement in the next column means a DM may move to a less preferred state temporarily in order to reach a more preferred one eventually. The disimprovement by opponents means that other DMs may choose to move to a less preferred state in order to block the focal DM's unilateral improvements. For mathematical definitions, references, and other details, see Fang et al. (1993).

Table 1 is about here

To determine the stability and equilibrium status of a state, significant calculations are needed. Without an efficient decision support system, it would be extremely hard to carry out a stability analysis of any conflict model. To alleviate the calculation burden and enhance the applicability of the graph model methodology, the DSS, GMCR II, is designed to operationalise the aforesaid solution concepts and permits the calibration and stability analysis of conflict models (Fang et al., 2003a, 2003b). GMCR II furnishes a friendly user interface, requires minimal input, and completes calculations as well as analyses in an expeditious manner. This DSS can be beneficially applied to three main situations listed as follows (Kilgour and Hipel, 2005).

1) Analysis and simulation tool for conflict participants: GMCR II can be used in simulation or role-playing exercises that aim to achieve a better understanding or prediction of real world conflicts. 
2) Analysis and communication tool for mediators: GMCR II can be utilized by mediators to reconcile opposing viewpoints, create a more harmonious atmosphere in which to carry out negotiations, and assist in conducting and settling a dispute more effectively.

3) Analysis tool for a third party or a regulator: GMCR II can be used by other interested parties, such as representatives of a third party or a regulator, as a helpful mechanism to understand the conflict and perhaps seek fact-binding or legal-binding rules.

\subsection{The Analytic Hierarchy Process}

Incorporating not only quantitative but also qualitative criteria during a decisionmaking process, the Analytic Hierarchy Process (AHP) (Saaty, 1980, 1982, 1995, 2001) is an effective multicriteria decision making technique that allows a DM to structure his or her decisions hierarchically and accommodates his or her personal experience, logical judgement, and even individual imaginations in the decision-making process. This technique has been broadly applied to many different aspects of problems areas (Vidal et al., 2010; Sadeghi-Niaraki et al., 2011; Yu et al., 2011). A review of the applications and methodological developments of AHP can be found in Ishizaka and Labib (2011).

The major idea underlying AHP is to streamline complex decision problems by breaking them down into hierarchies with fundamental elements. Usually, a typical hierarchy includes 1) a focus level, specifying the overall objective of the decision problem; 2) a criteria level, also called a factor level, identifying all important criteria; 3 ) a sub-criteria level, used in some complicated situations in order to provide more detailed insights of certain criteria (for extremely complex cases, there may exist several subcriteria levels); and 4) an alternative level, listing possible alternatives. Figure 1 illustrates such a typical hierarchy.

Figure 1 is about here

Next, pairwise comparison matrices are constructed for each criterion (factor) at the same level. The matrices contain the relative priorities of elements. Note that at different levels, these elements represent different objects: criteria, sub-criteria, or alternatives. For 
example, for a certain criterion (or sub-criterion) $X$ with $t$ elements below it: $Y_{1}, Y_{2}, \ldots, Y_{t}$, a pairwise comparison matrix can be made as illustrated in Table 2. In this matrix, $y_{i j}$ provides the pairwise comparison result of elements $Y_{i}$ and $Y_{j}$ with respect to element $X$. Therefore, it is natural to have: 1) $y_{11}=y_{22}=\ldots=y_{t t}=1$; and 2) $y_{i j}=1 / y_{j i}(i, j=1,2, \ldots, t)$.

Table 2 is about here

In AHP, a scale of " 1 " to "9" is adopted to conduct non-quantitative pairwise comparisons of two elements (Saaty, 1980, 1982, 1995, 2001). In this scale system, "1" indicates equal importance of two elements contributing to the upper level property, "9" means absolute importance of one element over another, and a value between "1" and "9" provides an in-between importance measurement of one element over another. For detailed descriptions of the 9-scale measurement system, see Saaty $(1980,1982,1995$, 2001). In the last decade, many concerns, such as weakness in the symmetry of negative and positive knowledge perception, have been raised about this 9-scale system. Therefore, alternative scale systems have been developed (Ma and Zheng, 1991, Donegan et al., 1992). In this paper, priority calculations are first carried out with the traditional 9-scale system, and, then, verified with two popular alternative scales (Beynon, 2002). The sensitivity analysis results are discussed in Section IV.C.

After the establishment of the pairwise comparison matrices, a so-called eigenvalue technique is employed to calculate the weights of overall relative priorities for each element. The consistency of the comparison matrices is tracked by a Consistency Ratio (CR). According to Saaty (1995), the consistency ratio should be less than $5 \%, 8 \%$, and $10 \%$ for a $3 \times 3$ matrix, a $4 \times 4$ matrix, and matrices of higher orders, respectively. Finally, by employing a linear additive aggregation procedure, the global priority of each element relative to the overall objective is derived based on all the weights generated in the previous procedure.

\subsection{The Integrated Approach}

This paper integrates an AHP based preference elicitation approach into a graph model. Figure 2 provides a simple comparison between the adapted version and the standard AHP approach. As can be seen in Figure 2(b), the overall purpose is to obtain the 
preference ranking of each DM whereby the feasible states are ordered from most to least preferred with ties being allowed. Instead of Criteria, this approach takes the DMs' influence powers into consideration. The powers then affect each DM's preference ranking.

Figure 2 is about here

More specifically, the structure of the adapted AHP approach is depicted in Figure 3. Detailed explanations are given next for the four hierarchies in this structure.

1) The Preference Ranking level contains all DMs considered in the conflict model. Instead of only one objective as in the standard AHP approach, this level specifies that the objectives are to obtain preference rankings for all DMs. Then, the preference analysis contained in the following steps is carried out from each DM's viewpoint separately.

2) The influence power level furnishes different DMs' influence powers over the entire situation from each DM's standpoint. By the same pairwise matrix and eigenvalue technique as the traditional AHP, a weight list is obtained to illustrate the power strength for all DMs based on a certain DM's assessment.

3) The option level lists all options under each DM's control. At this level, priority weights of all options will be obtained. Moreover, comparisons can be further decomposed into a sub-hierarchy model if the complexity of the problem warrants.

4) The actions/states level displays a series of action profiles, characterized by combinations of " 0 " and " 1 " against the options, where a " 0 " indicates a corresponding option is not chosen and a "1" stands for the option being selected. The overall preference ranking is thus determined by multiplying option priority weights and action status. After all DMs' relative preferences are elicited, they are then fed into GMCR II for further stability analyses.

Figure 3 is about here

Next, our strategic analysis of the port congestion problem in Western Canada aims to provide structural insights into this important issue from a third-party perspective. The analytical results indicate that it would be beneficial for regulators to make strategic 
investment in expanding port capacities and for relevant stakeholders to lobby government agencies for a better resolution. To conduct this analysis, the graph model methodology helps to put the problem into perspective, the AHP approach is employed to elicit preference rankings for each DM, and the DSS GMCR II allows for expeditious calculations of stability and equilibrium under diverse solution concepts as described in Section II.A and listed in Table 1.

\section{Modeling the Canadian West Coast Port Congestion Conflict}

In this section, a graph model is established to investigate the Canadian west coast port congestion problem. Subsequently, the proposed AHP structure is used to derive the relative preference input for the conflict model.

\subsection{Model Description}

The point in time that was selected for modeling the conflict is the beginning of October 2006. Four DMs are considered in this model: Canadian government (CA), United States government (US), Chinese government (CN), and Traders (TD). DMs and their corresponding options are listed in Table 3. As the graph model is designed to handle conflict situations at a strategic level, the choices listed below are given as general options. By substituting a general option into a set of more specific options, one could carry out a more detailed strategic analysis. However, the added complexity may not improve the clarity of the strategic insights that can be garnered. For a lower operational level analysis of the issue, the overall scope of the problem has to be further restricted and different methodologies (e.g., cost-benefit analysis) have to be entertained so that meaningful trade-offs can be examined.

Table 3 is about here

As mentioned in the introduction section, this research aims to assist the Canadian government to solve the congestion problem and take advantage of opportunities from the situation. Hence, CA's decisions are the focal point here. The three options for CA are to expand the capacities in Port of Prince Rupert, Port Metro Vancouver, or the other ports (east coast ports such as Port of Montreal and Port of Halifax). As the key strategic companion of CA, US has relied on Canadian west coast ports for a long time, and would 
like to continue utilizing these Canadian ports to ease its own transportation congestion. Furthermore, this model considers mainly the impacts of US's actions on CA. No matter which US ports are expanded, the results conceived by CA are the same. Therefore, the options for US are simplified to two: carrying out expansion plans on US ports or seeking other solutions. China is selected to be the representative for all fast-growing Asian trading partners, as China has now become one of the world's biggest economies due to its efficient labour costs. In addition to the Canadian and the US ports, $\mathrm{CN}$ is considering taking its own initiative to build a superport in Mexico. As one of the DMs, Traders refer to all shippers involved in this problem, such as manufacturers, exporters, importers, carriers, and third-party logistics providers. The options of TD are to choose which gateway to use for their current and future trade to North America. A more detailed discussion of these options is furnished later when preference elicitation is considered in Section III.C.

\subsection{Generation of Feasible States}

Except for China, which has only one option under its control, each DM has to choose at least one option: Canada has to expand its port capacities in one or more locations in response to the rising container volume; the US has to choose at least one of its options, expanding its own port capacity, finding other solutions to relieve the bottleneck situation, or both; and Traders have to select at least one of their options.

As for the "Option dependence" method embedded in GMCR II, Traders would like to choose US as the gateway only when US expands its own ports, to select CA as the gateway when Canada addresses its expansion plan in one of its three options, and to choose Mexico as the gateway unless China builds its own superport there. By using the foregoing techniques in GMCR II to remove infeasible patterns, 105 feasible states are retained out of 512 ( or $2^{9}$ ) mathematically possible states.

\section{3. $\quad$ Preference Ranking by the Modified AHP Approach}

Based on the list of DMs and options in Table 3, a hierarchy structure of this conflict model is given in Figure 4, which is employed to elicit relative preference rankings for each DM as explained below. Note that the consistencies of all calculations are confirmed 
using the guidelines in Saaty (1995) and discussed further with alternative scale systems at the end of Section IV.

Figure 4 is about here

\section{1) Canada's standpoint}

From Canada's standpoint, US is the most powerful DM, followed by Canada, then China, and with Traders exerting the least control over the situation. Accordingly, the pairwise comparison matrix for influence powers is formed as shown in Table 4 along with the ranking result (weights).

Table 4 is about here

At the option level, the expansion of the Port Metro Vancouver is definitely the first choice for Canada as Vancouver is Canada's flagship port and the most diversified port on the continent. As a matter of fact, Vancouver had planned to construct a third berth at Deltaport at Roberts Bank to increase its capacity by 400,000 TEUs to 1.3 million TEUs. But the federal government recently delayed this construction and requested more environmental impact studies (Ryan, 2006a).

Due to the strategic location and potential to offer efficient access to the North American market, the Port of Prince Rupert becomes another alternative. In fact, the Government of Canada already had the intent to build a container terminal there (Government of Canada, 2005). Some extra special features of the Port of Prince Rupert attract more attention from different parties. For example, its deep natural harbour provides the possibility of handling jumbo containerships; sailing times from Prince Rupert to China's main ports are about 24 to 60 hours shorter than from other west coast ports (Ryan, 2005); it has the safest west coast harbour with extensive capacity to expand (Port of Prince Rupert Authority, 2006). However, this alternative also faces many obstacles. The main issues include: 1) Remoteness of the location: Prince Rupert is about 500 miles north of Vancouver; 2) Lack of infrastructure: The Canadian National Railway (CNR) provides the only land connection to the port; 3) Aboriginal issues: A tribal group has threatened to file lawsuits to stop the progress of the port expansion plan due to the violation of aboriginal land rights; 4) Some shipping lines are reluctant to add this port 
into their shipping routes because of additional piloting costs (Machalaba, 2006; Ryan, 2006a).

Besides these two west coast ports, other Canadian ports have also gained prominence recently. It is known that the Ports of Montreal and Halifax have started to handle significant container businesses originating from the US Midwest. Furthermore, their geographic locations and existing surplus capacities provide them with competitive advantages over other alternatives (Ryan, 2006b).

With respect to the US's options, it does not really matter for Canada if US chooses to expand its own ports or finds some other solutions for the congestion problem. When it comes to Traders' options, the most important concern for Canada is that they select Canada as one of their trading gateways. The other two choices, US and Mexico gateways, are much less preferred and do not make much difference for Canada. The pairwise comparison matrices for all these options for each DM are then constructed, and the ranking weights are also calculated as shown in Table 5.

Table 5 is about here

2) US's standpoint

Table 6 provides the pairwise comparison matrix and ranking results for influence power from US's viewpoint. US thinks of itself as the most powerful DM, China as slightly more powerful than Canada due to its rapid growth and its increasing impacts on the world trade, and Canada as somewhat more powerful than the Traders.

Table 6 is about here

At the option level for the US, the Port of Prince Rupert is the most preferred, followed by the Port Metro Vancouver, and then other ports. Although the Port of Prince Rupert is remotely located in Northern $\mathrm{BC}$, the railway system provides a direct link to Chicago with very few stops on the way. Therefore, the rail-transit time is likely about the same as the land route from Los Angeles to Chicago, even with a longer distance (Machalaba, 2006). By squeezing out unnecessary delays at other crowded ports, the entire transportation time from China to the US Midwest could possibly be reduced from 35-40 days to only about 20 days if the route via the Port of Prince Rupert is taken (Pitts, 2006). 
In order to capture the booming Asian trade, US has to expand its own ports, especially its west coast ports, such as Los Angeles-Long Beach ports and Seattle-Tacoma ports, which handled more than 87 percent of the west coast's container volume in 2006 (Sowinski, 2007). However, due to the extremely expensive investment of expansion, some other approaches have been entertained. For instance, since 2005, the Ports of Los Angeles and Long Beach have been growing their PierPass Offpeak gates to shift cargo operations to off-peak hours in order to alleviate serious congestions at the ports, on the freeway, and in the neighbouring communities. This program now handles about $55 \%$ of all container traffic volume at these two ports without incurring significant investment into port infrastructures [PierPass.org, 2011].

As for the options of Traders, US most prefers that they choose US as the gateway so it can capture more profits than Canada. Mexico would be the last choice due to the lack of supporting infrastructure, particularly transportation systems. The pairwise comparison and ranking results for each DM's options from the US perspective are thus determined and illustrated in Table 7.

Table 7 is about here

\section{3) China's standpoint}

The Chinese government thinks the order of DMs' influence power from most to least is US, China, Canada, and Traders (Table 8).

Table 8 is about here

From the point of view of the Chinese government for Canadian ports, the Port of Prince Rupert, due to its shortest distance to Asia and future expansion potentials, naturally becomes the best alternative. Port Metro Vancouver would be the second choice because of its existing container capacity and handling experience. In addition, some east coast ports, such as Halifax, also gain attention from China for the possibility of bypassing congestion on the west coast. For China, whatever US does, either expanding ports or exploring other methods, does not make any difference, as long as the serious bottleneck situation can be lessened so that their goods could be transported to their destinations instead of simply being piled up on the west coast. Building their own deepwater superport in Mexico is another potential resolution for China (Pitts, 2006). 
Therefore, the relative preference rankings for each DM's options from China's viewpoint are derived as shown in Table 9.

Table 9 is about here

\section{4) Traders' standpoint}

From Traders' standpoint, US, again, is the most powerful party, followed by Canada and themselves. China is the least powerful party (Table 10).

Table 10 is about here

For Traders, any port that can handle their goods would be attractive. As their goods shipped to US west coast ports are being piled higher and higher, Canadian ports are definitely good choices, especially the Port of Prince Rupert. Furthermore, for the reason of capacity surplus, some Canadian east coast ports gain more attention from different Traders than the Port Metro Vancouver. Again, to the extent that the west coast congestion problem is concerned, the two options controlled by US do not make any difference for Traders. Moreover, since US already has a much more developed infrastructure system than Mexico, it is a better gateway choice than Mexico, unless China develops its own deep-water superports in Mexico (Pitts, 2006). The pairwise comparison matrices and the corresponding weights for each DM's options from Traders' standpoint can hence be obtained as illustrated in Table 11.

Table 11 is about here

\section{5) Overall ranking}

By aggregating results obtained from each individual DM's perspective, the overall ranking weights are as listed in Table 12. As mentioned above, the weights for the Actions/States level are calculated by multiplying the related influence power by the option weight. For example, the Action/State weight for Canada choosing to expand the Port of Prince Rupert is $0.204 \times 0.268=0.054672 \approx 0.055$.

Table 12 is about here 
Now, all feasible states are treated as 105 alternatives and ranked accordingly in the AHP framework from each DM's perspective. Taking one of the predicted equilibria in Table 13, state 84, as an example, the preference value for CA can be computed as $1 \times 0.055+1 \times 0.125+1 \times 0.024+0 \times 0.331+1 \times 0.331+1 \times 0.084+0 \times 0.006+1 \times 0.039$ $+1 \times 0.006=0.664$. From these numerical preference values, one can derive the ordinal preference ranking for each DM. The preference information is then input into the GMCR II analysis engine to conduct stability analyses, which provide a wide range of individual stability and equilibrium information for each state under different solution concepts.

\section{ANALYTICAL RESUlTs: STRUCTURAL INSIGHTS AND INTERPRETATION}

\section{1. $\quad$ Predicted Resolutions}

Given the preference profiles generated in Section III, GMCR II examines all of the six stabilities for each feasible state. Among the 105 feasible states, only states 84 and 98 are predicted to be stable for all DMs under Nash, GMR, SMR, SEQ, and certain limitedmove stability as given in Table 1 in Section II.A. These two states are thus referred to as the predicted strong equilibria, or possible resolutions (Table 13). In Table 13, a "1" indicates that the option is chosen by the DM controlling this option, and a " 0 " means that the corresponding option is not selected. Different combinations of " 1 's" and " 0 's" illustrate DMs' diverse choices in the corresponding states. Generally speaking, the more solution concepts under which a state is predicted to be equilibrium, the more likely this state may actually turn out to be a resolution in reality. As the solution concepts GMR and SMR are only applicable to very conservative focal DMs, they tend to predict many stable states, resulting in a large number of equilibria (Fang et al. 1993). As such, our following analysis and interpretation are restricted to the two strong equilibria, states 84 and 98, which are more likely to occur in reality. For these two equilibria, there exist three distinct commonalities: 1) Canada performs expansion plans in all of its three options; 2) China builds its superport in Mexico; and 3) Traders continue choosing Canada as one of their trade gateways.

Table 13 is about here 
In Canada's case, this is exactly what happened after the point in time for which this model was built. On October 11, 2006, Canadian Prime Minister Stephen Harper announced the Asia-Pacific Gateway and Corridor Initiative (APGCI), with an initial investment of $\$ 591$ million over the next eight years on ports, roads, rails and other infrastructure to improve trading access to Asia-Pacific markets (Pacific Gateway Updates, 2009a). In order to further smooth the flow of international trade through Canada's west coast, an additional \$233.5 million “Asia-Pacific Gateway and Corridor Transportation Infrastructure Fund" is promised to improve the road and rail connections (Prince Rupert Port Authority, 2006, Brooks, 2007). The 2007 Canadian Budget included a further commitment of $\$ 410$ million, which brings the total federal funding for APGCI to more than $\$ 1$ billion (Pacific Gateway Updates, 2009a). On June 1, 2007, in a speech to the 70th annual conference on the Federation of Canadian Municipalities, the Prime Minister announced a \$33-billion infrastructure funding plan, among which one of the most critical projects is "the Asia-Pacific gateway and Corridor Initiative to bring Canada into the booming Far East through the West Coast ports" (Office of the Prime Minister, 2007). In October 2007, the Speech from the Throne further confirmed an infrastructure program, the Building Canada Plan, to support Canada's long-term growth by investing in the transport and trade hubs (Government of Canada, 2007). Moreover, the Government of Canada and Province of British Columbia have also been working with public and private sector agencies "to advance various initiatives to improve infrastructure, labour and service reliability of the Pacific Gateway" (Pacific Gateway Updates, 2009b). By March 2009, a total value of $\$ 15$ million had been invested by the partners in the Pacific Gateway (Pacific Gateway Updates, 2009a).

In January 2010, a new shipping berth was opened at Deltaport, Canada's largest container terminal. The capacity of the Port Metro Vancouver facility was increased by $50 \%$ because of this new berth (Canada's Pacific Gateway, 2010). In September 2010, the Government of Canada announced an investment of \$2.5 million in the Prince Rupert Port Authority's Fairview Terminal project to provide shore power capacity to container ships. This project will enable Prince Rupert to be the first Canadian port to offer shore power for container ships (The Government of Canada, 2010). As of the year 2010, on the east coast of Canada, the Halifax Port Authority had invested \$100 million during the 
previous five years, and planned to invest over $\$ 225$ million over the next five years. The private sector also invested over $\$ 250$ million in port-related infrastructure up until 2010 (Halifax Port Authority, 2010).

In the meantime, China has been working actively to open and develop NAFTA shipping ports in Mexico. This will allow products to be transported across the Pacific Ocean between China and Mexico at the ports of Manzanillo and Lazaro Cardenas, and then to service the North American market through San Antonio, Texas (Corsi, 2006).

\subsection{Status Quo Analysis}

As one of the important analysis tools in GMCR, status quo analysis is used to address the dynamic dimension of the conflict and provides insights into the evolution of the conflict over time. Basically, this analysis tracks the moves of the problem from the starting point of the conflict, passing through transitional states, and finally reaching the equilibrium (Li et al., 2005).

Table 14 shows the state transition from the status quo state to equilibrium 98. Note that the arrows in the table indicate moves made by the corresponding DMs. At the status quo, the US has started to seek possible ways of dealing with the serious congestion problem, and Traders are now choosing US and CA as their trading gateway. Then, CA makes the first move by investing in the expansion plan in all of its three options. Next, seeing that $\mathrm{CA}$ is making relentless efforts to improve the situation, US decides to continue its own expansion plan and drops the other option under its control. Subsequently, CN still thinks a superport in Mexico is to its benefit and decides to act on this plan, and thus, TD adds this superport as one of their gateways in addition to the other two existing choices.

Table 14 is about here

\subsection{Sensitivity Analyses}

In a sensitivity analysis, one makes meaningful changes in one or more of the model parameters to ascertain how this affects the final results. For example, in a conflict analysis investigation, an analyst may wish to determine if sensible alterations to the preferences of one or more of the DMs changes the final equilibria. If the equilibria 
remain essentially the same, then the strategic findings are said to be robust with respect to the preference changes. In many conflict studies, uncertainty in preference information indicates what specific sensitivity analyses should be executed. A main advantage of the Graph Model for Conflict Resolution is that one can immediately ascertain the strategic impacts of these preference changes.

Consider now the case study being addressed in this paper. Because preference information used in the AHP analysis was obtained from the published literature and the authors' understanding of the dispute, there is some uncertainty present. Accordingly, two sensitivity analyses are carried out using sensible changes in the judgement matrices. Specifically, the first sensitivity analysis examines the uncertainty in judgement matrices by varying their pairwise comparison entries, and the other one explores two alternative scale systems to Saaty's original 1-9 scales.

\section{1) Sensitivity Analysis on Pairwise Judgement Matrices}

As an example, the pairwise judgement matrix for influence powers from Canada's standpoint in Table 4 has been exhaustively examined by varying the CA-CN entry from 2 to 4 , the CA-TD entry from 4 to 6 , US-CA entry from 4 to 6 , US-CN from 6-8, US-TD from 8 to 9, and CN-TD from 1 to 3 (with remaining entries being set up as the reciprocal values of the corresponding entries, e.g., if $y_{i j}=3$, then $y_{j i}=1 / 3$ ). This extensive examination portrays a reasonable picture of how the uncertainty in judgement matrices may affect the DMs' preference rankings and the resulting equilibria. Computational results indicate that when the preference information is changed, the predicted strong equilibria remain as states 84 and 98 as given in Table 13. Hence, the equilibria are robust or resilient with respect to these judgement matrix changes.

\section{2) Sensitivity Analysis on Scale Systems}

As outlined by Saaty (1995), consistency ratios should be less than 5\%, $8 \%$, and 10\% for $3 \times 3,4 \times 4$, and higher-order matrices, respectively. For all of the pairwise matrices presented earlier (Tables 4-11), Saaty's original 1-9 scale system is employed. Analytical results confirm that most of the consistency ratios satisfy these requirements except for two $3 \times 3$ matrices (Tables 5.a and 7.a), which yield a consistency ratio of 0.07 .

Accordingly, two alternative scales discussed by Beynon (2002) were employed for executing a sensitivity analysis. Beynon (2002) indicates that the original 1-9 scale may 
exhibit weakness in the presence of the symmetry of negative and positive knowledge perception, whereas alternative scales offer certain benefits in this case. Therefore,

preference priorities are re-calculated using the following two suggested alternative scales:

1) '9/9-9/1' scales (Ma and Zheng, 1991), namely $9 /(10-k)$, with $k=1, \ldots, 9$.

2) $\phi$ mapping (Donegan et al., 1992), where the relevant scales satisfy $\phi: k \rightarrow \exp \left(\tanh ^{-1}\left(\frac{k-1}{9}\right)\right)$, with $k=1, \ldots, 9$.

With these two new scales, all consistency ratios are effectively controlled within the threshold of 0.05 . Recalculations with these alternative scale systems result in nearly identical state rankings (preferences), and the final strong equilibria remain the same as the original analysis.

Hence, these sensitivity analyses confirm the robustness of the strategic findings and validate the structural insights obtained from our investigation.

\section{CONCLUSIONS}

In this paper, the Canadian west coast port congestion problem is analyzed from a conflict-analysis perspective. During the past few decades, the number of containers being transported to or from west coast ports has been boosted extensively. Amidst a period of booming economics, this situation of congestion is not only a challenging problem, but also a significant opportunity for Canada. This study aims to assist the Canadian government in seeking possible ways to ease the congestion and to maximize benefits.

In addition to the Canadian government, the options and preferences of the US government, the Chinese government, and traders are all considered. The AHP approach is adapted to elicit preferences for each DM, and the preference rankings are then fed into the conflict model within the framework of a DSS, GMCR II, for further stability analysis. This research sheds strategic insights into the conflict under consideration. Practically, the analysis suggests potential resolutions where DMs would take their own actions to deal with the situation: Canada would expand its port facilities on the west coast, China 
would build its superport in Mexico, and traders would then continue to select Canadian west coast ports for trading purposes.

\section{REFERENCES}

Beynon, M. (2002). An analysis of distributions of priority values from alternative comparison scales within AHP, European Journal of Operational Research, 140(1): 105-118.

Brooks, M.R. (2007). Addressing gaps in the transportation network: Seizing Canada's continental gateway advantage. The Conference Board of Canada. Ottawa, Ontario, Canada.

Canada's Pacific Gateway (2010). Asia-Pacific gateway and corridor initiative: Reaches a milestone. [Online] Available from: http://www.pacificgateway.gc.ca/media/ documents/en/APGCI-Reaches-a-Milestone.pdf [Access date: October 04, 2011].

Chang, C.W., Wu, C.R., Lin, C.T., and Chen, H.C. (2007). An application of AHP and sensitivity analysis for selecting the best slicing machine. Computers and Industrial Engineering, 52(2): 296-307.

Corsi, J.R. (2006). Red China Opens NAFTA Ports in Mexico, Human Events.com, July 18. [Online] Available from: http://www.humanevents.com/article.php?print= yes\&id=16077 [Access date: October 04, 2011].

Donegan, H.A., Dodd, F.J., and McMaster, T.B. (1992). A new approach to AHP decision-making. The Statistician, 41, 295-302.

Fang, L., Hipel, K.W. and Kilgour, D.M. (1993). Interactive Decision Making: The Graph Model for Conflict Resolution. New York: Wiley.

Fang, L., Hipel, K.W., Kilgour, D.M. and Peng, X. (2003a). A decision support system for interactive decision making, part 1: model formulation. IEEE Transactions on Systems, Man and Cybernetics, Part C, 33(1): 42-55.

Fang, L., Hipel, K.W., Kilgour, D.M. and Peng, X. (2003b). A decision support system for interactive decision making, part 2: analysis and output interpretation. IEEE Transactions on Systems, Man and Cybernetics, Part C, 33(1): 56-66. 
Government of Canada (2005). Major investment in Prince Rupert Port expansion. April 15. [Online]. Available from: http://www2.news.gov.bc.ca/archive/20012005/2005OTP0064-000525.htm. [Access date: October 04, 2011].

Government of Canada (2007). Strong leadership: A better Canada (Speech from the Throne). October 16, 2007, Ottawa, Ontario, Canada.

Halifax Port Authority (2010). Infrastructure enhancements underway at the south end container terminal. January 26. [Online]. Available from: http://www.portofhalifax.ca/english/news-and-events/news-archives/2010-pressreleases/index.html\#southend. [Access date: October 04, 2011].

Ishizaka, A., and Labib, A. (2011). Review of the main developments in the analytic hierarchy process. Expert Systems with Applications, 38(11): 14336-14345.

Ke, Y. Li, K.W., and Hipel, K.W. (2007). The integration of a modified AHP preference ranking approach and the graph model analysis. In Proceedings of the 2007 IEEE International Conference on Systems, Man, and Cybernetics, pp. 1830-1835, Montreal, Canada.

Kilgour, D.M., Fang, L., and Hipel, K.W. (1996). Negotiation support using the decision support system GMCR. Group Decision and Negotiation, 5(4-6): 371-383.

Kilgour, D.M. and Hipel, K.W. (2005). The graph model for conflict resolution: past, present, and future. Group Decision and Negotiation, 14(6): 441-460.

Li, K.W., Kilgour, D.M., and Hipel, K.W. (2005). Status quo analysis of the graph model for conflict resolution, Journal of the Operational Research Society, 56(6): 699-707.

Ma, D. and Zheng, X. (1991). 9/9-9/1 scale method of AHP. In: Proceedings of the Second International Symposium on the AHP. Pittsburgh, PA, I, pp. 197-202.

Machalaba, D. (2006). Tiny British Columbia port aims to be new venue for China trade. The Wall Street Journal, Vol. CCXLVIII No. 32, August 8.

Office of the Prime Minister, Prime Minister Stephen Harper lays out national infrastructure plan for municipalities. June 1. [Online]. Available from: http://pm.gc.ca/eng/media.asp?id=1677 [Access date: October 04, 2011]. 
Pacific Gateway Updates. (2009a), Canada, BC, Partners deliver new infrastructure funding. March 27. [Online]. Available from: http://www2.news.gov.bc.ca/news releases_2005-2009/2009OTP0058-000553.htm [Access date: October 04, 2011].

Pacific Gateway Updates. (2009b). Infrastructure investment in the North Shore. March 27. [Online]. Available from: http://www2.news.gov.bc.ca/news_releases_20052009/2009OTP0058-000553-Attachment1.pdf [Access date: October 04, 2011].

PierPass.org (2011), Marine terminal operators at the Ports of Los Angeles and Long Beach postpone TMF adjustment to August 1. [Online]. Available from: http://pierpass.org/2011/06/27/marine-terminal-operators-at-the-ports-of-los-angelesand-long-beach-postpone-tmf-adjustment-to-august-1/ [Access date: October 04, 2011]

Pitts, G. (2006). Will west coast ports miss the boat? Globe and Mail - Report on Business, March 6.

Prince Rupert Port Authority. (2006). Federal announcement opens new opportunities for Prince Rupert Port. October. [Online]. Available from: http://www.rupertport.com/pdf/newsreleases/federal\%20announcement $\% 20$ opens $\% 20$ n ew\%20opportunities\%20for\%20prince\%20rupert\%20port\%20nr.pdf [Access date: October 04, 2011].

Ryan, L. (2005). Canadian ports join the infrastructure catch-up game. Canadian Transportation \& Logistics, 108(3): 7-8.

Ryan, L. (2006a). Fighting time. Canadian Transportation \& Logistics, 109(3): 30-31.

Ryan, L. (2006b). Ports report 'our turn to deal'. Canadian Transportation \& Logistics, 109(9): 36-37.

Saaty, T.L. (1980). The Analytic Hierarchy Process: Planning, Priority Setting, Resource Allocation, New York: McGraw-Hill.

Saaty, T.L. (1982). Decision Making for Leaders: The Analytical Hierarchy Process for Decisions in a Complex World, Belmont, CA: Lifetime Learning Publications. 
Saaty, T.L. (1995). Transport planning with multiple criteria: The analytic hierarchy process applications and progress review. Journal of Advanced Transportation, 29(1): $81-126$.

Saaty, T.L. (2001). The Analytic Network Process: Decision Making with Dependence and Feedback, 2nd ed., Pittsburgh: RWS Publications.

Sadeghi-Niaraki, A. Varshosaz, M., Kim, K. and Jung, J.J. (2011) Real world representation of a road network for route planning in GIS. Expert Systems With Applications, 38(10): 11999-12008.

Smyrlis, L. (2005). Pressure on transportation requires Ottawa's attention. Canadian Transportation \& Logistics, 108(10): 10-12.

Sowinski, L.L. (2007). What business leaders need to know about: West coast logistics. World Trade, 20(3): 56-59.

Transport Canada (2005). Canada's Pacific Gateway Strategy. October 21. [Online] Available from: http://www.tc.gc.ca/eng/mediaroom/releases-nat-2005-05-gc013e4038.htm\#bg. [Access date: October 04, 2011].

Transport Canada (2010). Government of Canada Funds Green Port Project in Prince Rupert. September 14. [Online] Available from: http://www.tc.gc.ca/eng/mediaroom/ releases-2010-h103e-6078.htm. [Access date: October 04, 2011].

Vidal, L.-A., Sahin, E., Martelli, N., Berhoune, M., and Bonan, B. (2010) Appling AHP to select drugs to be produced by anticipantion in a chemotherapy compounding unit. Expert Systems With Applications, 37(2): 1528-1534.

Woo, S.-H., Pettit, S.J., Kwak, D.-W., and Beresford, A.K.C. (2011). Seaport research: A structured literature review on methodological issues since the 1980s. Transportation Research Part A: Policy and Practice, 45(7): 667-685.

Yu, Xiaobing, Guo, S., Guo, J. and Huang, X. (2011) Rank B2C e-commerce websites in e-alliance based on AHP and fuzzy TOPSIS. Expert Systems With Applications, 38(4): 3550-3557. 


\section{Figure captions}

Figure 1. A sample hierarchy

Figure 2. Comparison of the standard and adapted AHP.

Figure 3. The structure of the adapted AHP approach

Figure 4. An adapted AHP model for eliciting preferences for the west coast congestion problem. 
Table 1. Stability definitions and human behaviour (Adapted from Fang et al., 1993)

\begin{tabular}{|c|c|c|c|}
\hline Definition & Description & Foresight & Disimprovements \\
\hline Nash stability (Nash) & $\begin{array}{l}\text { If a DM cannot unilaterally move to a more } \\
\text { preferred state. }\end{array}$ & Low & Never \\
\hline $\begin{array}{l}\text { General } \\
\text { metarationality } \\
(\text { GMR) }\end{array}$ & $\begin{array}{l}\text { If all of a DM's unilateral improvements are } \\
\text { sanctioned by its opponents' subsequent unilateral } \\
\text { moves. }\end{array}$ & \multirow{3}{*}{ Medium } & \multirow{2}{*}{ By opponents } \\
\hline $\begin{array}{l}\text { Symmetric } \\
\text { metarationality (SMR) }\end{array}$ & $\begin{array}{l}\text { If all of a DM's unilateral improvements are still } \\
\text { sanctioned, even after a possible response by the } \\
\text { original DM. }\end{array}$ & & \\
\hline $\begin{array}{l}\text { Sequential stability } \\
\text { (SEQ) }\end{array}$ & $\begin{array}{l}\text { If all of a DM's unilateral improvements are } \\
\text { sanctioned by its opponents' subsequent unilateral } \\
\text { improvements. }\end{array}$ & & Never \\
\hline $\begin{array}{l}\text { Limited-move } \\
\text { stability }\left(L_{h}\right)\end{array}$ & $\begin{array}{l}\text { A fixed number }(h) \text { of state transitions are } \\
\text { contemplated; all DMs are assumed to act } \\
\text { optimally by backward induction. }\end{array}$ & Variable & \multirow[t]{2}{*}{ Strategic } \\
\hline $\begin{array}{l}\text { Non-myopic stability } \\
\text { (NM) }\end{array}$ & $\begin{array}{l}\text { The limiting case of the limited-move stability as } \\
\text { the number of state transition approaches } \infty \text {. }\end{array}$ & High & \\
\hline
\end{tabular}

Table 2. A sample matrix for pairwise comparison

\begin{tabular}{|c|cccc|}
\hline $\boldsymbol{X}$ & $Y_{1}$ & $Y_{2}$ & $\cdots$ & $Y_{t}$ \\
\hline$Y_{1}$ & $y_{11}$ & $y_{12}$ & $\cdots$ & $y_{1 t}$ \\
$Y_{2}$ & $y_{21}$ & $y_{22}$ & $\cdots$ & $y_{2 t}$ \\
$\cdots$ & $\cdots$ & $\cdots$ & $\cdots$ & \\
$Y_{t}$ & $y_{t 1}$ & $y_{t 2}$ & $\cdots$ & $y_{t t}$ \\
\hline
\end{tabular}

Table 3. DMs and corresponding options

\begin{tabular}{|c|ll|}
\hline Decision Makers & \multicolumn{2}{|c|}{ Options } \\
\hline \multirow{3}{*}{ Canadian government (CA) } & 1. & PPR: Expansion plan in the Port of Prince Rupert \\
& 2. & PMV: Expansion plan in the Port Metro Vancouver \\
& 3. & OP: Other ports, either west or east coast ports \\
\hline United States government & 4. & EX: Expansion plan for its own ports \\
(US) & 5. & OS: Other solutions, such as shift cargo operations to off-peak hours \\
\hline Chinese government (CN) & 6. & MS: Develop own superport in Mexico \\
\hline \multirow{2}{*}{ Traders (TD) } & 7. & US: US gateway \\
& 8. & CA: Canadian gateway \\
& 9. & ME: Mexican gateway \\
\hline
\end{tabular}


Table 4. The pairwise comparison matrix for influence powers from Canada's standpoint

\begin{tabular}{|c|c|c|c|c|c|}
\hline & CA & US & CN & TD & Weight \\
\hline CA & 1 & $1 / 5$ & 3 & 5 & 0.204 \\
\hline US & 5 & 1 & 7 & 9 & 0.661 \\
\hline $\mathrm{CN}$ & $1 / 3$ & $1 / 7$ & 1 & 2 & 0.084 \\
\hline TD & $1 / 5$ & $1 / 9$ & $1 / 2$ & 1 & 0.050 \\
\hline
\end{tabular}

Table 5. Pairwise comparison matrices for each DM's options from Canada's standpoint

\begin{tabular}{|c|c|c|c|c|}
\hline CA & PPR & PMV & OP & Weights \\
\hline PPR & 1 & $1 / 3$ & 3 & 0.268 \\
\hline PMV & 3 & 1 & 4 & 0.614 \\
\hline OP & $1 / 3$ & $1 / 4$ & 1 & 0.117 \\
\hline
\end{tabular}

a) CA's options

\begin{tabular}{|c|c|c|c|}
\hline US & EX & OS & Weights \\
\hline EX & 1 & 1 & 0.500 \\
\hline OS & 1 & 1 & 0.500 \\
\hline
\end{tabular}

b) US's options

\begin{tabular}{|c|c|c|c|c|}
\hline TD & US & CA & ME & Weights \\
\hline US & 1 & $1 / 7$ & 1 & 0.111 \\
\hline CA & 7 & 1 & 7 & 0.778 \\
\hline ME & 1 & $1 / 7$ & 1 & 0.111 \\
\hline
\end{tabular}

c) Traders' options

Table 6. The pairwise comparison matrix for influence powers from US's standpoint

\begin{tabular}{|c|c|c|c|c|c|}
\hline & CA & US & CN & TD & Weight \\
\hline CA & 1 & $1 / 3$ & $1 / 2$ & 2 & 0.159 \\
\hline US & 3 & 1 & 3 & 4 & 0.510 \\
\hline CN & 2 & $1 / 3$ & 1 & 2 & 0.226 \\
\hline TD & $1 / 2$ & $1 / 4$ & $1 / 2$ & 1 & 0.104 \\
\hline
\end{tabular}

Table 7. Pairwise comparison matrices for each DM's options from US's standpoint

\begin{tabular}{|c|c|c|c|c|}
\hline CA & PPR & PMV & OP & Weights \\
\hline PPR & 1 & 3 & 4 & 0.614 \\
\hline PMV & $1 / 3$ & 1 & 3 & 0.268 \\
\hline OP & $1 / 4$ & $1 / 3$ & 1 & 0.117 \\
\hline \multicolumn{5}{|r}{}
\end{tabular}

a) Canada's options

\begin{tabular}{|c|c|c|c|}
\hline US & EX & OS & Weights \\
\hline EX & 1 & 2 & 0.667 \\
\hline OS & $1 / 2$ & 1 & 0.333 \\
\hline
\end{tabular}

b) US's options

\begin{tabular}{|c|c|c|c|c|}
\hline TD & US & CA & ME & Weights \\
\hline US & 1 & 2 & 4 & 0.558 \\
\hline CA & $1 / 2$ & 1 & 3 & 0.320 \\
\hline ME & $1 / 4$ & $1 / 3$ & 1 & 0.122 \\
\hline
\end{tabular}

c) Traders' options 
Table 8. The pairwise comparison matrix for influence powers from China's standpoint

\begin{tabular}{|c|c|c|c|c|c|}
\hline & CA & US & CN & TD & Weight \\
\hline CA & 1 & $1 / 4$ & $1 / 2$ & 2 & 0.143 \\
\hline US & 4 & 1 & 2 & 6 & 0.526 \\
\hline CN & 2 & $1 / 2$ & 1 & 2 & 0.240 \\
\hline TD & $1 / 2$ & $1 / 6$ & $1 / 2$ & 1 & 0.092 \\
\hline
\end{tabular}

Table 9. Pairwise comparison matrices for each DM's options from China's standpoint

\begin{tabular}{|c|c|c|c|c|}
\hline CA & PPR & PMV & OP & Weights \\
\hline PPR & 1 & 2 & 4 & 0.571 \\
\hline PMV & $1 / 2$ & 1 & 2 & 0.286 \\
\hline OP & $1 / 4$ & $1 / 2$ & 1 & 0.143 \\
\hline
\end{tabular}

a) Canada's options

\begin{tabular}{|c|c|c|c|}
\hline US & EX & OS & Weights \\
\hline EX & 1 & 1 & 0.500 \\
\hline OS & 1 & 1 & 0.500 \\
\hline
\end{tabular}

b) US's options

\begin{tabular}{|c|c|c|c|c|}
\hline TD & US & CA & ME & Weights \\
\hline US & 1 & $1 / 3$ & $1 / 2$ & 0.163 \\
\hline CA & 3 & 1 & 2 & 0.540 \\
\hline ME & 2 & $1 / 2$ & 1 & 0.297 \\
\hline
\end{tabular}

c) Traders' options

Table 10. The pairwise comparison matrix for influence powers from Traders' standpoint

\begin{tabular}{|c|c|c|c|c|c|}
\hline & CA & US & CN & TD & Weight \\
\hline CA & 1 & $1 / 2$ & 2 & 1 & 0.224 \\
\hline US & 2 & 1 & 4 & 2 & 0.449 \\
\hline CN & $1 / 2$ & $1 / 4$ & 1 & 1 & 0.136 \\
\hline TD & 1 & $1 / 2$ & 1 & 1 & 0.191 \\
\hline
\end{tabular}

Table 11. Pairwise comparison matrices for each DM's options from Traders' standpoint

\begin{tabular}{|c|c|c|c|c|}
\hline CA & PPR & PMV & OP & Weights \\
\hline PPR & 1 & 3 & 2 & 0.550 \\
\hline PMV & $1 / 3$ & 1 & 1 & 0.210 \\
\hline OP & $1 / 2$ & 1 & 1 & 0.240 \\
\hline
\end{tabular}

a) Canada's options

\begin{tabular}{|c|c|c|c|}
\hline US & EX & OS & Weights \\
\hline EX & 1 & 1 & 0.500 \\
\hline OS & 1 & 1 & 0.500 \\
\hline
\end{tabular}

b) US's options

\begin{tabular}{|c|c|c|c|c|}
\hline TD & US & CA & ME & Weights \\
\hline US & 1 & $1 / 2$ & 2 & 0.311 \\
\hline CA & 2 & 1 & 2 & 0.493 \\
\hline ME & $1 / 2$ & $1 / 2$ & 1 & 0.196 \\
\hline
\end{tabular}

c) Traders' options 
Table 12. Overall ranking weights

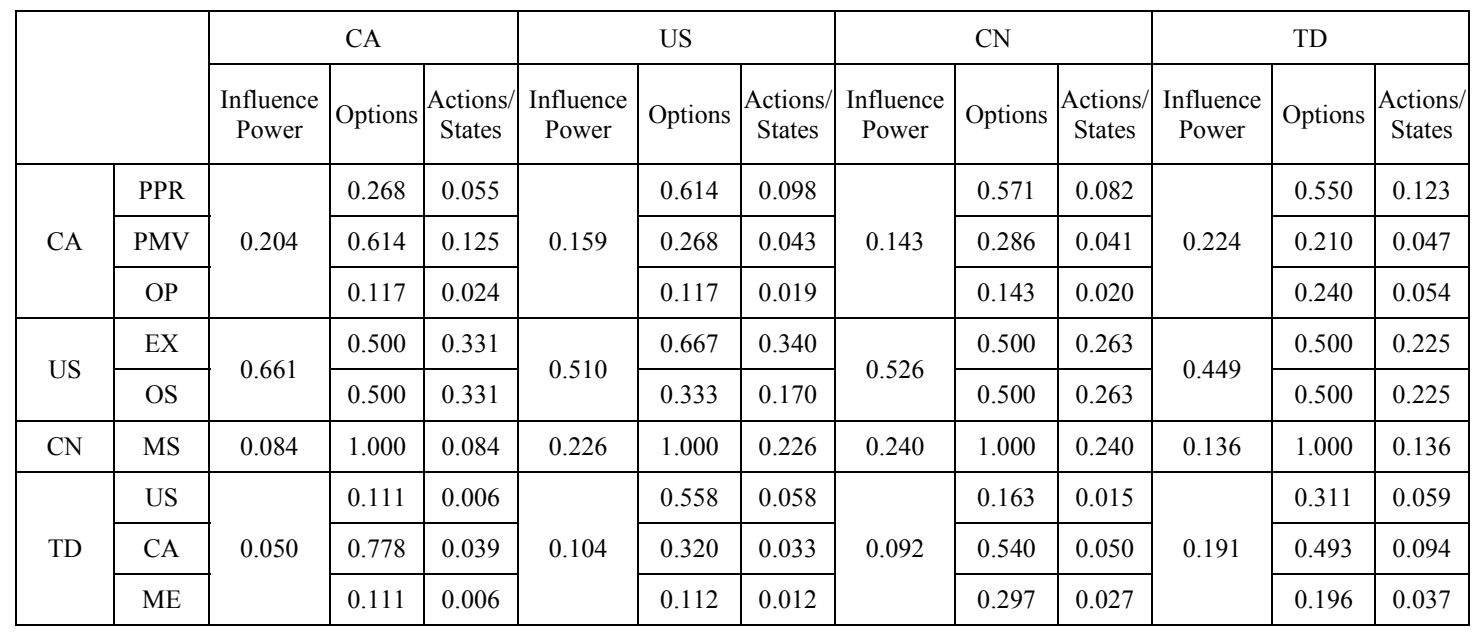

Table 13. Possible resolutions

\begin{tabular}{l|ll}
\hline & 84 & 98 \\
\hline CA: & & \\
1. PPR & 1 & 1 \\
2. PMV & 1 & 1 \\
3. OP & 1 & 1 \\
US & & \\
4. EX & 0 & 1 \\
5. OS & 1 & 0 \\
CN & & \\
6. MS & 1 & 1 \\
TD & & \\
7. US & 0 & 1 \\
8. CA & 1 & 1 \\
9. ME & 1 & 1 \\
\hline
\end{tabular}

Table 14. Status quo analysis for Canadian west coast congestion problem

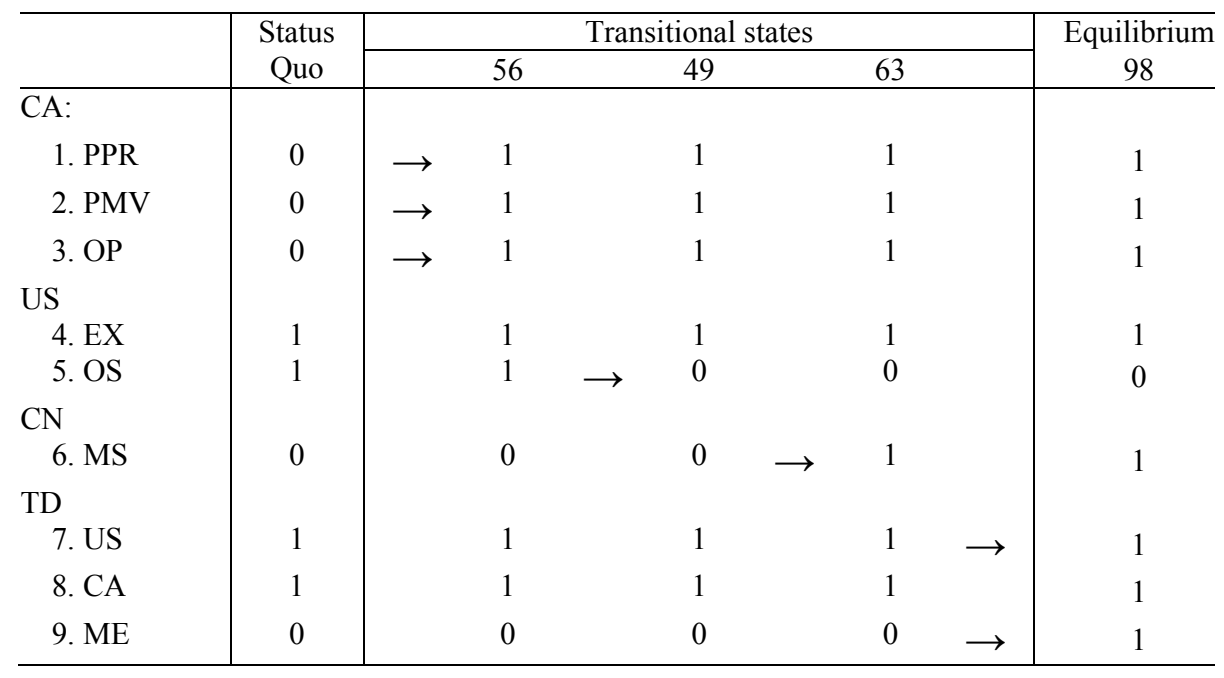

